Itinéraires Itinéraires

Littérature, textes, cultures

2012-1 | 2012

Genres et avant-gardes

\title{
Hester Albach, Léona, héroine du surréalisme
}

Traduit du néerlandais par Arlette Ounanian, Arles, Actes Sud, 2009, 307 pages

Clara Manco

\section{OpenEdition}

12 Journals

Édition électronique

URL : http://journals.openedition.org/itineraires/1351

DOI : 10.4000/itineraires.1351

ISSN : 2427-920X

Éditeur

Pléiade

\section{Édition imprimée}

Date de publication : 1 septembre 2012

Pagination : 187-189

ISBN : 978-2-296-55776-5

ISSN : $2100-1340$

\section{Référence électronique}

Clara Manco, « Hester Albach, Léona, héroine du surréalisme », Itinéraires [En ligne], 2012-1 | 2012, mis en ligne le 01 septembre 2012, consulté le 22 septembre 2020. URL : http://journals.openedition.org/ itineraires/1351; DOI : https://doi.org/10.4000/itineraires.1351

Ce document a été généré automatiquement le 22 septembre 2020.

\section{(c) $($ () $\ominus$}

Itinéraires est mis à disposition selon les termes de la licence Creative Commons Attribution - Pas d'Utilisation Commerciale - Pas de Modification 4.0 International. 


\section{Hester Albach, Léona, héroine du surréalisme}

Traduit du néerlandais par Arlette Ounanian, Arles, Actes Sud, 2009, 307 pages

\section{Clara Manco}

\section{RÉFÉRENCE}

Hester Albach, Léona, héroine du surréalisme, traduit du néerlandais par Arlette Ounanian, Arles, Actes Sud, 2009, 307 pages.

1 Un soir de grande détresse, par une chance extraordinaire, une narratrice anonyme découvre, derrière un radiateur de son nouvel appartement, une copie de Nadja d'André Breton. Elle vient de s'installer à Paris, tout autour d'elle est encore vide, et le livre est une édition originale de 1928: ces hasards interpellent la lectrice, qui se laisse immédiatement entraîner par le charme mystérieux de l'ouvrage. Aussitôt, c'est la figure de Nadja qui la fascine, cette «âme errante» dont les rencontres avec Breton forment le nœud du livre, et qui semble habitée d'un mystère impénétrable. Elle dévore leurs aventures parisiennes, les "pétrifiantes coïncidences » qui entourent chacune de leurs rencontres, leur complicité qui ne suffit pas, pourtant, à attacher André à Nadja. Dans Nadja, André finit par rompre neuf jours plus tard pour enfin trouver le vrai amour.

2 Mais est-ce là toute la vérité ? Malgré le pacte initial de sincérité de Nadja, que Breton annonce comme une « maison de verre », le texte reste trop opaque pour être honnête. C'est ainsi que notre hérö̈ne se lance dans une passionnante enquête, un jeu de piste sur les traces de la véritable Nadja... si tant est qu'elle ait bien existé.

3 Après quelques tâtonnements, d'indice en indice, de fausse route en rencontre fortuite, c'est le miracle : sa trace est retrouvée. Elle s'appelle Léona Camille Ghislaine Delcourt, elle vient de Lille et s'est installée à Paris sans un sou, abandonnant derrière elle une fille naturelle. Enfin, derrière le chef-d'œuvre apparaitt la muse. Et quel destin pour 
cette jeune fille un peu perdue qui se dit « médium ", qui peine à joindre les deux bouts, cette jeune fille aux "yeux de fougère", lumineuse à la fois de "détresse " et «d'orgueil »! Entre sa rencontre avec Breton, son amour sans condition pour le poète et jusqu'aux plus sordides asiles d'aliénés, les coïncidences se multiplient, les hasards n'en sont pas, tout fait sens. Des codes secrets de l'alchimie à l'énigmatique «langue des oiseaux", des noms de rue les plus anodins aux lieux où l'Histoire a laissé sa marque, de symboles en métaphores, tout dans Nadja comme dans la vie de Léona est signe à déchiffrer.

Il s'agit donc pour Hester Albach, écrivain d'origine néerlandaise née en 1953, de faire surgir de l'obscurité la figure d'une femme exceptionnelle et artiste incomprise à partir de quelques photos et de rares documents et témoignages (intégrés au récit en guise de preuves - et en clin d'œil à l'esthétique de Nadja). Son enfance, la guerre, l'accouchement imprévu qui fait d'elle une fille-mère, la pauvreté parisienne après l'ivresse de sa nouveauté, la drogue, la prison et la folie, et surtout l'ordinaire et l'extraordinaire qui se mêlent sans cesse: nous voilà suivant les "pas perdus " de Léona... qui ne le sont pas tant que ça. Réhabiliter une existence injustement niée, c'est le parcours que nous propose donc la narratrice, dont plus d'une fois le destin propre semble croiser celui de son héroïne. Sans chercher à accuser Breton, sans cesser au contraire de rendre hommage à son génie, Hester Albach lève le voile sur le destin de la muse abandonnée, victime de l'incompréhension d'une société trop prompte à compter pour fou un esprit libre. Qu'aurait pu être Léona si elle avait été prise au sérieux ? Elle était muse, mais ne méritait-elle pas d'être bien davantage ?

Hester Albach cherche ainsi à reconstituer dans ce livre le rôle exact qu'a joué Léona Delcourt dans l'écriture de Nadja. Dans la lignée des récents mouvements féministes de réhabilitation du rôle des femmes, longtemps jugé négligeable mais désormais revu en leur faveur, dans les diverses histoires littéraires et artistiques, le but de l'auteur (qui revendique qu'il s'agit là d'« une affaire de femmes») est explicitement de redéfinir le rôle de " muse » de Léona, de lui rendre son génie propre absorbé par celui de Breton, voire de lui reconnaître une place de co-auteur de Nadja. La Léona véritable ainsi mise au jour est très attachante et on ne peut que se réjouir de l'intérêt qu'elle suscite. L'auteur accomplit le quasi-miracle de tirer de l'oubli cette existence effacée. Les nombreux fac-similés mêlés au récit, le recoupement des témoignages directs et inédits, l'accès à des archives exceptionnelles garantissent souvent, pour le lecteur, la scientificité des faits avancés. La présentation de ces faits dans l'ordre de leur découverte est aussi particulièrement ingénieuse, à la fois pour appuyer la crédibilité d'une hypothèse, citer des sources de façon élégante, mais également partager avec le lecteur le plaisir de l'enquête. C'est un réel plaisir en effet, comparable à celui de lire un roman policier, que de se plonger ainsi dans cette aventure, de dénouer peu à peu les nœuds de l'écriture volontairement cryptique de Breton. À l'investigation scientifique vient s'ajouter une forte dimension romanesque et poétique: des pans entiers de l'histoire de Léona flottent dans une imprécision de sources, un flou d'allusions ou une abondance de conjectures non argumentées (malgré un effort général de précision). Si la limite entre faits avérés et interprétation reste vague, c'est sans doute cela qui permet réellement d'entrer dans la personnalité labyrinthique de Léona, d'en saisir intimement les enjeux et les drames, une manière encore de lui rendre sa vie. C'est d'ailleurs avant tout comme romancière et nouvelliste qu'Hester Albach s'est faite connaître dans son pays, dès 1975 avec Les Débuts (porté même à l'écran) ou plus récemment avec Une relation saine ou Une Goutte d'or -Léona, hérö̈ne du surréalisme est son 
premier ouvrage traduit en français. Il est quelque peu regrettable que l'importance et la qualité scientifiques de ses découvertes sur «l'héroïne du surréalisme » en soient ainsi diminuées, mais la richesse de l'ouvrage tient à cela que, sans perdre de vue la vocation référentielle de la biographie, donc sa nécessaire précision, vient s'ajouter un autre type de vérité, plus proche peut-être de celle de Nadja: la force d'une évocation poétique.

6 Nadja, "millefeuille de récits", véridique et trompeur à la fois, hante Hester Albach comme une obsession, et c'est un délice de se perdre avec elle dans le labyrinthe de son énigme. Léona a bien existé, mais elle semble nécessairement s'excéder elle-même, dépasser sa propre réalité : l'éternité du mythe de Nadja semble en être à jamais inséparable.

\section{AUTEURS}

CLARA MANCO

Université Paris-Sorbonne (Paris IV), CRLC 